\section{Resultados preliminares de um estudo qualitativo sobre a interação entre mãe e criança desnutrida grave, no contexto da hospitalização}

\section{Preliminary results of a qualitative study of interaction between mothers and seriously malnourished hospitalized children}

Marisa Amorim Sampaio ${ }^{1}$

Ana Rodrigues Falbo ${ }^{2}$

Maria do Carmo Camarotti ${ }^{3}$

Maria Gorete Lucena de Vasconcelos 4

1 Unidade de Neonatologia. Pós-Graduação. Instituto Materno Infantil Prof. Fernando Figueira-IMIP. Rua dos Coelhos, 300. Recife, PE, Brasil. CEP 50.070-550. E-mail: marisasampaio@hotmail.com

2 Departamento de Pesquisa. Instituto Materno Infantil Prof. Fernando Figueira-IMIP, Recife, PE, Brasil

3 Faculdade de Ciências Médica. João Pessoa, PB, Brasil

4 Departamento de Enfermagem. Universidade Federal de Pernambuco. Recife, PE, Brasil.

\section{Abstract}

Objectives: to analyze the features of the interactive psychodynamics of the interaction of mothers with seriously malnourished hospitalized children.

Methods: qualitative research based on psychoanalysis, using semi-structured interviews, observations and video recordings. Content analysis was applied to representative topics.

Results: a study was conducted of eight pairs consisting of a biological mother and seriously malnourished child aged between six and 18 months of age hospitaized at the Instituto Materno Infantil Prof. Fernando Figueira-IMIP, in the city of Recife, State Pernambuco, Brazil. Three central topics were identified, illustrating the process of becoming a parent, its importance for interactive psychodynamics, factors that interfere in the formation/rupture of the mother-child bond, its repercussions on the situation of malnutrition and the way it manifests itself in a context of hospitalization.

Conclusions: from the preliminary analysis, the mutual influence of the mother and the child on the construction of the interaction and the complexity of the functional disharmonies is reinforced, suggesting that extreme states of malnutrition may be associated to nutritional privation and/or errors, as well as the experiences of psycho-affective privation or excess. The observation of mother-child interaction at critical moments, such as malnutrition and hospitalization, may help family and health professionals to understand how the illness develops, and suggest the need for integrated health care.

Key words Object attachment, Mother-child, relations, Malnutrition, Child development, Psychoanlysis

\section{Resumo}

Objetivos: analisar elementos da psicodinâmica interativa entre mães e crianças desnutridas graves hospitalizadas.

Métodos: método qualitativo baseado no referencial psicanalítico, com entrevistas semi-estruturadas, observações e filmagens. Empregou-se a análise de conteúdo, elegendo-se temas representativos.

Resultados: foram acompanhadas oito díades de crianças entre seis e 18 meses de idade e a mãe biológica, internadas no Instituto Materno Infantil Prof. Fernando Figueira-IMIP, em Recife, Pernambuco. Identificaram-se três temas, os quais ilustram o processo de parentalidade, sua importância na psicodinâmica interativa da díade, fatores que podem ter interferido na construção/ruptura do vínculo, sua contribuição para a situação de desnutrição e expressão na hospitalização.

Conclusões: a partir da análise preliminar, reforça-se a influência mútua de mãe e filho na construção da interação e a complexidade dos distúrbios funcionais, sugerindo que estados extremos de desnutrição podem estar associados a faltas elou falhas nutricionais, bem como a vivências de privação ou excesso psicoafetivo. A observação da interação mãe-criança em momentos críticos, como desnutrição e hospitalização, pode auxiliar a família e a equipe de saúde na compreensão do processo de adoecimento e da necessidade do atendimento integral.

Palavras-chave Apego ao objeto, Relações mãefilho, Desnutrição, Desenvolvimento infantil, Psicanálise 


\section{Introdução}

Interação pode ser definida como a ação recíproca entre dois fenômenos, ${ }^{1}$ enfatizando a noção de reciprocidade e interdependência, partindo-se do princípio que a relação da criança com a mãe (ou cuidador) se dá em um processo bi-direcional, constituído por um conjunto de fenômenos dinâmicos que ocorrem ao longo do tempo entre mãe e criança. ${ }^{2,3}$

$\mathrm{O}$ estudo da interação mãe-criança abrange extensa gama de abordagens; a psicanálise traz contribuição importante para o estudo desse fenômeno, uma vez que as interações envolvem não só características manifestas dos envolvidos, como também elementos representacionais imaginários e fantasmáticos. ${ }^{4}$ Por elementos representacionais imaginários e fantasmáticos compreende-se os conteúdos psíquicos inconscientes, como idealizações, representações e valores transmitidos transgeracional e intergeracionalmente, manifestados através do corpo, da linguagem e dos afetos. ${ }^{5}$

A interação está no fundamento da subjetivação; o sofrimento psíquico na primeira infância geralmente está associado a dificuldades no processo interativo, resultando em desarmonias funcionais nos registros de troca, ilustrados pela oralidade (incorporação pela via oral, como no caso da alimentação), invocação (relação com o outro através da comunicação) e especularidade (relação através das trocas envolvendo o olhar). ${ }^{6}$

Considerou-se interação como um processo no qual um conjunto de fenômenos dinâmicos ocorre entre os atores envolvidos ou implicados, retrospectiva e prospectivamente.

A desnutrição infantil é um processo multicausal com condicionantes biológicos, emocionais e sociais, incluído o vínculo mãe-filho. ${ }^{7,8}$ Para a compreensão da situação nutricional da criança, a alimentação deve ser avaliada para além das necessidades fisiológicas, ${ }^{7,9}$ uma vez que os primeiros conflitos interacionais encontram expressão na esfera da alimentação. ${ }^{6,9,10}$

Buscou-se abordar os aspectos da carência (pobreza) no plano real (falta da comida, erro alimentar) e sua conseqüência biológica (desnutrição), investigando significados que ilustrassem como a falta real associada à falta simbólica pode ter influenciado na interação da díade.

A avaliação da interação mãe-criança é um instrumento importante no acompanhamento do crescimento e desenvolvimento infantil, principalmente em situações em que há risco e descontinuidade desse processo. ${ }^{6} \mathrm{~A}$ interação da díade foi estudada buscando-se compreender o papel desempenhado por mãe e criança, focando-se no contexto da desnutrição e hospitalização. A desnutrição foi tomada como uma situação de risco não apenas socioeconômico, mas também emocional.

\section{Métodos}

A pesquisa qualitativa apoiada na psicanálise delineou a abordagem teórico/metodológica do estudo, realizado no Instituto Materno Infantil Prof. Fernando Figueira-IMIP, região metropolitana central do Recife, Pernambuco, entidade não-governamental, filantrópica, sem fins lucrativos.

Os dados foram obtidos entre novembro de 2006 e abril de 2007. Acompanharam-se oito díades durante a hospitalização, atendendo ao critério de saturação das respostas ou reincidência das informações. $^{11}$

A situação de internação evoca um despertar de vivências da mãe e da criança que podem informar sobre o passado da díade, bem como permite observar a importância da interação mãe-criança como fator para a instalação e perpetuação da desnutrição.

A seleção foi intencional, de modo a incluir díades adequadas à aquisição das informações propostas nos objetivos do estudo. Tendo em vista a representatividade e a diversidade na investigação, refletindo a totalidade nas múltiplas dimensões, ${ }^{12,13}$ buscou-se abordar o fenômeno da interação mãecriança em díades com o mesmo pano de fundo socioeconômico, porém que pudessem ilustrar com riqueza as diversas nuances do processo interativo (díades com/sem dificuldades aparentes na interação, díades com rede social vasta/precária, díades com dificuldade/facilidade na aquisição de alimento, entre outros elementos).

Foram incluídas crianças com desnutrição grave primária (índice peso/altura $<-3$ escore $\mathrm{z}$, utilizando o padrão de referência Organização Mundial da Saúde (OMS), ${ }^{14}$ e/ou presença de edema simétrico envolvendo no mínimo os pés), sem mal-formações, síndrome genética, retardo mental grave e/ou transtornos invasivos do desenvolvimento, pois se estimou que outra doença pudesse atrapalhar o processo de vinculação mãe-criança.

A idade das crianças variou de 6 a 18 meses, período em que a criança já tem consciência da mãe, do outro da maternagem, e em que ocorrem o desmame e as primeiras manifestações da angústia de castração, eventos esses que podem fornecer importantes elementos para análise da dinâmica interativa. 
Priorizando aspectos do rigor ético e metodológico da pesquisa qualitativa, como a triangulação, contextualização e auditabilidade, ${ }^{15}$ foram utilizadas entrevistas individuais semi-estruturadas, observações (filmadas ou não) e anotações retiradas do prontuário médico da criança, permitindo a triangulação de técnicas e teorias.

Utilizou-se roteiro norteador, construído com base em elementos maternos, familiares (incluindo o pai), da criança e da díade, orientando a condução das entrevistas, sem impedir o aprofundamento de aspectos relevantes ao entendimento do fenômeno. As entrevistas e observações foram conduzidas, gravadas, filmadas e transcritas.

Numa tentativa de aproximação entre pesquisa qualitativa e psicanálise, a "transferência" e "contratransferência", fenômenos explicados pela última, foram considerados na relação intersubjetiva, sendo essa característica central do método qualitativo, considerada não como obstáculo, mas instrumento inevitável e clareador. ${ }^{16}$

Considera-se que os significados de cada mãe estão inseridos e se referem a um determinado contexto, só podendo ser compreensíveis mediante aproximação da realidade individual. A análise contextualizada e complexa desses significados buscou a articulação entre teoria, método e criatividade diante do objeto, refletindo o critério de objetivação. ${ }^{11}$

Considerou-se a singularidade dos sujeitos (díade e pesquisadora), do contexto das entrevistas e observações, e da transferência desenvolvida, não passíveis de repetição em sua integralidade.

A representatividade dos significados e a confiabilidade interna foram buscadas através do debate com as orientadoras e colaboradores da pesquisa, visando a troca de impressões e informações. A confiabilidade visou também avaliações críticas das participantes, de modo que o produto final se aproximasse de um texto negociado, resultante de um processo interativo envolvendo tanto o entrevistado como o pesquisador na produção do conhecimento. ${ }^{11,13,17}$

\section{Análise dos dados}

O processo de análise dos dados ocorreu desde o trabalho de campo, formatando a coleta e auxiliando na compreensão do papel exercido por pesquisadora e entrevistada.

Buscou-se compreender o lugar que a criança parecia ocupar no universo materno, bem como o lugar em que a mãe parecia colocar a pesquisadora, caracterizando seu estilo interativo, fruto da repetição de experiências precoces, em função do discurso materno, das demandas da criança, da psicodinâmica interativa da díade e da transferência e contratransferência.

A condução do fenômeno transferencial marca a diferença entre a técnica como modalidade de tratamento em psicanálise e o uso do método de investigação orientado por essa. A transferência não foi passível de interpretação, no aspecto psicanalítico, uma vez que o objetivo foi compreender e não trabalhar o fenômeno transferencial, diferente da técnica interpretativa no tratamento psicanalítico, que busca pôr em evidência e modificar o curso das motivações inconscientes das repetições transferenciais. $^{18}$

A análise dos dados buscou a correlação dos elementos obtidos no prontuário, nas entrevistas, observações, filmagens e diário de campo, reunidos em dossiês.

Foi utilizada a metodologia análise de conteúdo, associada à técnica de análise da enunciação, realizando-se recortes transversais de falas e atos de fala da díade, elegendo-se categorias ou temas representativos dos níveis de interação mãe-criança. ${ }^{19}$

Ao longo do tratamento dos dados foi realizado trabalho de descrição, análise e interpretação, coexistindo e auxiliando na compreensão do material obtido. $^{12}$

\section{Aspectos éticos}

A pesquisa está de acordo com a Declaração de Helsinque e com as Normas da Resolução 196/96 do Conselho Nacional de Ética em Pesquisa e Conselho Nacional de Saúde. Obteve a aprovação prévia do Comitê de Ética em Pesquisa em Seres Humanos do IMIP. A coleta de dados foi realizada com prévia assinatura do termo de consentimento livre e esclarecido pelas mães das crianças participantes ou pelo seu responsável, quando a mãe era menor de idade.

Nos casos em que foi observada importante dificuldade na interação mãe-criança, a ponto de interferir negativamente na evolução da criança, foi recomendada consulta com a psicóloga responsável pela enfermaria. O mesmo procedimento foi válido para os casos em que a mãe solicitou consulta psicológica (para si mesma e/ou criança) ou solicitação vinda de qualquer outro membro da família ou da equipe hospitalar.

\section{Resultados}

Entre as 11 mães contatadas, três foram excluídas: 
uma por desistência logo no início da pesquisa; uma considerada inelegível devido à dificuldade na fluência do discurso, e outra deixou o hospital antes da finalização das entrevistas e filmagens.

A idade das oito mães estudadas foi entre 15 e 47 anos, e a escolaridade variou da primeira série do ensino fundamental ao segundo ano do ensino médio. Apenas uma mãe era estudante e duas exerciam atividade fora do lar, uma em trabalho informal e outra canavieira com carteira assinada. Uma era solteira e outra separada, as demais mães coabitavam com o marido. Cinco dessas mulheres tinham um ou dois filhos, enquanto as demais tinham quatro, sete e quatorze filhos.

A maioria das mães tinha condição socioeconômica precária, característica compatível com o perfil da clientela do hospital estudado. Quanto ao suporte social, apenas uma recebia o Bolsa Família, outra o Bolsa Escola, uma usufruía o benefício do INSS de um irmão deficiente, e outra da aposentadoria do marido. A maior parte dessas famílias não teve acesso a esses programas políticos de auxílio.

Todas as mães referiram período(s) em que passaram dificuldade financeira, algumas chegando a passar fome. Diante disso, a família imediata (avós e tios das crianças) e vizinhos foram referidos como os responsáveis pelo apoio financeiro e emocional às díades.

A descoberta da gravidez trouxe mudanças na vida dos pais, em especial no aspecto financeiro e social. Em cinco das oito díades o casal ou um dos pais mudou-se, tendo em vista a melhoria do sustento financeiro da família com a chegada do novo membro. Nos casos em que ocorreu a mudança do casal, houve a perda do apoio da família imediata (avós e tios da criança). Algumas mães associaram o adoecimento ou a piora da criança à perda da proximidade geográfica/apoio emocional da família e/ou diminuição da atenção dispensada pelo marido após o início deste novo emprego. Outro aspecto referido por algumas dessas mães foi a necessidade de buscar trabalho fora do lar, comprometendo a atenção ao filho.

Com relação as crianças, cinco eram do sexo feminino e três do sexo masculino. Uma dessas foi a óbito ao longo do estudo. O tempo de internação variou entre 10 e 40 dias. A maioria dessas díades era do interior do estado de Pernambuco e apenas uma da Região Metropolitana do Recife. Todas haviam sido encaminhadas de outros hospitais da rede pública, após insucesso no tratamento da doença, nem sempre identificada pelo hospital de origem como desnutrição, principalmente nos casos em que a criança apresentava edema.
Mudança geográfica da família, sazonalidade da lavoura, desemprego, doença de um dos pais; esses aspectos parecem ter influenciado no desencadeamento da doença, interferindo na leitura e resposta da mãe quanto aos sinais interacionais da criança.

Até o presente estágio da análise dos dados foram identificados três temas, discriminados abaixo.

\section{Temática 1. O processo de construção da parentalidade}

- Construção da parentalidade ao longo da gestação por meio da interação mãe-feto;

- Vivência da parentalidade por meio da interação mãe-criança no domicílio, enfatizando os sinais interacionais e a alimentação.

Esse tema ilustra a complexidade transgeracional familiar e a riqueza de elementos que se conjugam nessa construção. Entre esses elementos, destacam-se experiências familiares maternas, o relacionamento com o companheiro, a descoberta e o desejo com a gravidez, bem como os papéis assumidos pelos pais na construção da maternidade/paternidade. As subcategorias ilustram particularidades das dimensões da parentalidade (exercício, experiência e prática da parentalidade $)^{20}$ e seus reflexos na interação mãecriança.

Como exemplos de experiências pessoais ou familiares maternas que pareceram marcar a parentalidade, destacam-se o fato de uma das mães e sua criança não serem registradas, bem como quatro mães que referiram perda significativa antes da gravidez da criança do estudo (aborto espontâneo ou provocado, morte de pai, morte da irmã). Uma dessas mães chegou a dar à filha o nome da irmã morta, sem adicionar o sobrenome do pai da criança. Três das mães foram orientadas por suas próprias mães (avós) a abortar a criança, opção rejeitada pelo casal, apesar da incerteza financeira deles.

\section{Temática 2. Vivência e retomada da parentalidade: interação mãe-criança na hospitalização}

- Sinais interacionais percebidos pela mãe, vividos no hospital;

- Adaptação da criança ao hospital em função do relacionamento com a mãe;

- Interação da díade entre si e com a pesquisadora: a construção de uma terceira história.

Esse tema ilustra a percepção e vivência dos sinais interacionais e seu papel no auxílio à díade na 
adaptação à hospitalização. Destaca também a narratividade, decorrente da hospitalização e da pesquisa qualitativa, auxiliando na percepção de si e do outro e seu reflexo na retomada e resignificação da parentalidade. Ilustra também que o adoecimento e a hospitalização podem favorecer a interação mãe-filho, atuando como fatores terapêuticos na retomada do vínculo e na experiência e prática da parentalidade.

Algumas díades pareciam compreender e responder aos sinais interacionais do parceiro numa comunicação diálogica, ${ }^{3}$ onde a mãe se dirigia à criança atribuindo-lhe um espaço temporal durante o qual o filho podia se organizar, responder e ser respaldado. No entanto, outras díades pareciam "duelar angustiadamente" ao longo da alimentação, atividade tomada na maioria das vezes, apenas em seu sentido funcional (ganho de peso), reforçado pela equipe de saúde e tomado pelas mães como único ou principal meio para saúde/alta hospitalar.

Curiosamente, algumas díades passaram a interagir de modo diferente ao longo da hospitalização, evidenciando-se a construção de novos significados às manifestações do parceiro, anteriormente não lidas ou sequer percebidas como sinais interacionais. Destaca-se o reflexo desse movimento na retomada de aspectos da parentalidade.

\section{Temática 3. Desnutrição e interação mãe- criança: significados criados em relação à doença e compreensão dessa a partir da interação com a criança e com o hospital}

Por fim, na temática 3, observa-se a fala materna trazendo à tona significados criados ao complexo processo de adoecimento, ilustrando a influência da interação da mãe com o filho e com a equipe de saúde na produção de significados à desnutrição.

Nenhuma das mães pareceu ter identificado a desnutrição como doença, apenas considerando como processo mórbido as intercorrências agudas e infecciosas (diarréia, pneumonia). Não pareciam associar o edema à desnutrição, uma vez que essa foi unanimemente referida como sinônimo de baixo peso ou perda de peso.

Entre os significados criados ao adoecimento, destacam-se: transmissão intra-uterina; leite artificial oferecido precoce e inadequadamente como causador dos sintomas infecciosos; anemia; reumatismo, problema renal (devido ao edema); "tipo de câncer".

\section{Discussão}

A interação mãe-criança é vastamente estudada mediante diferentes perspectivas teórico-conceituais e metodológicas, como constatado nas bases de dados pesquisadas. No entanto, pontua-se a carência de trabalhos enfocando a compreensão da dinâmica interativa da díade mãe-criança desnutrida grave no contexto da hospitalização.

O estudo buscou compreender, em uma realidade particular (desnutrição e hospitalização), a influência mútua de mãe e filho na construção da interação, observando esse fenômeno como uma associação de fatores, não em uma relação de causa-e-efeito.

Nas famílias acompanhadas, as quais tinham condição socioeconômica precária, a experiência e a prática da parentalidade ${ }^{20}$ incluíram a recorrente preocupação com a alimentação da criança, temendo a repetição da experiência de fome. Esse fato foi analisado sob dois diferentes aspectos: obstáculo à criação do filho e/ou amamentação, ou, pelo contrário, como incentivador do aleitamento. Em relação a esse último aspecto, o leite materno passou a figurar como único alimento oferecido diante do receio ou da falta real de comida, bem como da perspectiva do adoecimento infantil. O prolongamento do aleitamento materno, no entanto, considerando a dinâmica psicoafetiva, representa um transbordamento da função materna e a provável falha da função paterna, trazendo prejuízos à estruturação psíquica infantil. ${ }^{6,21}$

A experiência de falta real parecia balizar a constituição dos vínculos afetivos da maioria dessas famílias, marcados pela precariedade e fragilidade com que se iniciavam e se desfaziam, porém não sem prejuízos psíquicos à mãe, expressos na interação com o seu filho.

Outro fator que sugere ter influenciado negativamente na interação da díade foi a dificuldade de um dos pais ou de ambos em inserir o filho na linhagem de filiação, submetidos inconscientemente a uma determinação simbólica familiar que os ultrapassa, como nos casos da díade não registrada oficialmente e da criança que recebeu o nome da tia morta. Observa-se nesta dinâmica uma repetição que desloca os pais do lugar de interlocutores privilegiados da criança, resultando em obstáculos à experiência e prática da parentalidade. ${ }^{20,22}$

A parentalidade é um processo que se constrói, como um trabalho que põe em evidência a complexidade e as características paradoxais do fenômeno natural do parentesco. Esse processo organiza a percepção dos pais em face deles mesmos e do filho, e organiza igualmente a percepção que a criança tem a respeito dos pais. Desse modo, pais e filho têm papel ativo na construção da parentalidade, na qual a criança é inscrita e se inscreve. ${ }^{20}$ 
Observou-se também que a desnutrição parece ter influenciado no investimento da mãe na criança, e vice-versa, uma vez que a doença tornava a criança menos responsiva aos investimentos maternos, criando-se um ciclo vicioso bidirecional: diminuição da demanda infantil, com prejuízo ao investimento materno.

A psicopatologia alimentar reflete uma dinâmica interativa complexa e conflitiva, representada pelos seguintes aspectos: insuficiência ou excesso de investimento libidinal, falta de estímulos, descontinuidade da relação, incoerência na leitura e na resposta às solicitações, interação cronicamente vazia ou bruscamente esvaziada, enfim, irregularidades quantitativas e/ou qualitativas do vínculo. ${ }^{10,21}$ Nessas condições, a criança pode não se beneficiar da função materna de pára-excitação. ${ }^{10}$

Outro aspecto fundamental a ser considerado na compreensão dessa dinâmica conflitiva é a inadequação da função paterna enquanto terceiro fundamental da díade mãe-criança.

Entre as díades estudadas, esses aspectos, associados ou isolados, parecem ter interferido negativamente no diálogo mãe-filho. A adequada interação da díade pode se romper em determinadas situações, tornando a criança menos responsiva aos investimentos maternos e vice-versa., 32

Ao se observar a interação da díade, deve-se levar em consideração ao mesmo tempo a situação real da criança, a realidade psíquica dos parceiros da constelação familiar e a dimensão simbólica da parentalidade e da filiação. ${ }^{20,22}$

A análise preliminar dos dados reforça a influência mútua de mãe e filho na construção da interação ${ }^{3}$ e a complexidade dos distúrbios funcionais precoces, ${ }^{10}$ sugerindo que estados extremos de desnutrição podem estar associados não apenas às faltas e/ou falhas nutricionais, mas também a vivências de privação ou excesso psicoafetivo. ${ }^{6}$

$\mathrm{O}$ ato de alimentação da criança não é apenas uma atividade com fins nutritivos; reflete a doação afetiva da mãe, de seu imaginário e simbólico. ${ }^{3} \mathrm{O}$

\section{Referências}

1. Mazet P, Stoleru S. Manual de psicopatologia do recémnascido. Porto Alegre: Artes Médicas, 1990.

2. Pinto EB. Contribuição para a análise das interações precoces na perspectiva psicanalítica. In: Piccinini CA, Moura MLS, Ribas AFP, Bosa CA, Oliveira EA, Pinto EB, Schermann L, Chahon VL. Diferentes perspectivas na análise da interação pais-bebê/criança. Psicol Reflex Crit. 2001; 14: 478-80. investimento libidinal materno transforma o alimento em atrativo simbólico. Contrariamente, diante de trocas mecânicas e anônimas, a alimentação torna-se puramente operacional, referindo-se tão somente ao real do corpo infantil. ${ }^{3,6}$ É preciso assegurar na nutrição a sobrevida física da criança, sem por isso negligenciar a dimensão simbólica da alimentação e sua importância à estruturação psíquica e desenvolvimento infantil. Essa atividade proporciona a mãe e filho a experiência de feedback recíproco, com gratificações para ambos: o bebê reforça o narcisismo materno, enquanto a mãe dá suporte corporal e psíquico ao filho. ${ }^{23}$

A compreensão do lugar ocupado pela criança na problemática psíquica da mãe, do casal e na história transgeracional da família é fundamental no interjogo das interações posteriores, ${ }^{24}$ principalmente nas vividas em momentos críticos à díade, como diante da desnutrição e hospitalização. A retomada dessa problemática no hospital pode auxiliar a díade e a equipe de saúde na compreensão do processo de adoecimento.

A observação dos registros de troca díadicos precoces, possíveis indicadores de risco/plasticidade, enquanto determinantes na constituição subjetiva da criança e do futuro adulto, ${ }^{6,21,25}$ apontam a necessidade de cuidados integrais pela equipe de saúde, onde o hospital pode exercer importante papel na compreensão do adoecimento/desnutrição, na retomada do vínculo mãe-criança e na experiência e prática da parentalidade.

\section{Agradecimentos}

Às famílias participantes, à equipe de saúde da enfermaria "E" do IMIP, a Geisy Lima, Andréa Echeverria, Luciana Dubeux e a Coordenação de Aperfeiçoamento de Pessoal de Nível Superior (CAPES).

3. Ferreira SMSO. A interação mãe-bebê: primeiros passos [dissertação mestrado]. Recife: Programa de PósGraduação em Letras e Lingüística, do Departamento de Letras da Universidade Federal de Pernambuco; 1990.

4. Piccinini CA, Moura MLS, Ribas AFP, Bosa CA, Oliveira EA, Pinto EB, Schermann L, Chahon VL. Diferentes perspectivas na análise da interação pais-bebê/criança. Psicol Reflex Crit. 2001; 14: 469-85. 
5. Wendland J. A abordagem clínica das interações pais-bebê: perspectivas teóricas e metodológicas. Psicol Reflex Crit. 2001; 14: 45-56.

6. Cullere-Crespin G. A clínica precoce: o nascimento do humano. São Paulo: Casa do Psicólogo; 2004.

7. Nóbrega FJ. Vínculo mãe/filho. Rio de Janeiro: Revinter; 2005.

8. Temas Nutr. [Soc. Bras. Pediatr.] 2002; (2).

9. Lemes SO, Moraes DEB, Vítolo MR. Bases psicossomáticas dos distúrbios nutricionais na infância. $\mathrm{R}$ Nutr. [PUCCAMP] 1997; 10: 37-44.

10. Brazelton T, Cramer B, Kreisler L, Schappi R, Soulé M. A dinâmica do bebê. Porto Alegre: Artes Médicas; 1987.

11. Minayo MCS. O desafio do conhecimento. 9. ed. São Paulo: Hucitec; 2006.

12. Gomes R, Souza ER, Minayo MCS, Malaquias JV, Silva CFR. Organização, processamento, análise e interpretação de dados: o desafio da triangulação. In: Minayo MCS, Assis SG e Souza ER, organizadores. Avaliação por triangulação de métodos. Rio de Janeiro: FIOCRUZ; 2005. p. 185-221.

13. Minayo MCS, Deslandes SF, organizadores. Caminhos do pensamento: epistemologia e método. Rio de Janeiro: FIOCRUZ; 2002.

14. OMS (Organização Mundial de Saúde). Manejo da desnutrição grave: um manual para profissionais de saúde de nível superior e suas equipes de auxiliares, Brasília, DF; 1999.

15. Pinto EB. A pesquisa qualitativa em psicologia clínica. Psicol USP. 2004; 15: 71-80.

16. Lowenkron TS. O objeto da investigação psicanalítica. In: Herrmann F, Lowenkron TS, organizadores. Pesquisando com o método psicanalítico. São Paulo: Casa do Psicólogo; 2004. p. 21-31.
17. Fraser MTD, Gondim SMG. Da fala do outro ao texto negociado: discussões sobre a entrevista na pesquisa qualitativa. Paidéia: Cad Psicol Educ. 2004; 14: 139-52.

18. Thöma H, Kächele H, organizadores. Teoria e prática da psicanálise. Porto Alegre: Artes Médicas; 1992.

19. Bardin L. Análise de coneúdo. Lisboa Edições 70; 1977.

20. Silva MCP, organizador. Ser pai, ser mãe, parentalidade: um desafio para o terceiro milênio. São Paulo: Casa do Psicólogo; 2004.

21. Rohenkohl CMF. É possível formalizar os sinais patológicos na clínica com bebê? In: Encontro Latinoamericano dos Estados Gerais da Psicanálise, 2001. Disponível em URL: http://www.estadosgerais.org/encontro/formalizar_sinais_patologicos.shtml [2007 jun 10]

22. Bernardino LMF. O que a psicanálise pode ensinar sobre a criança, sujeito em constituição. São Paulo: Escuta; 2006.

23. Camarotti MC. De braços vazios: uma separação precoce. In: Rohenkohl CMF. A clínica com o bebê. São Paulo: Casa do Psicólogo; 2000. p. 50-62.

24. Lebovici S. O bebê, a mãe e o psicanalista. Porto Alegre: Artes Médicas; 1987.

25. Almeida MM. A clinical study of early feeding difficulties: risk and resilience in early mismatches within parent-infant relashionship [master's dissertation]. Londres: Tavistock Clinic and University of East London; 1993. 